\title{
Inheritance in Chrysanthemum morifolium Ramat.
}

\author{
F. A. Langton
}

AFRC Institute of Horticultural Research, Worthing Road, Littlehampton BN17 6LP, U.K.

A study was undertaken to determine whether inheritance in the bivalent-forming, hexaploid Chrysanthemum morifolium is diploid-like (selective chromosome pairing) or hexasomic (random chromosome pairing). Self-compatible genotypes, nulliplex for the dominant allele I (Carotenoid Inhibitor), were crossed with I-possessing cvs. Pink Marble and Pollyanne. Segregation ratios for the progenies of the Pollyanne (putative triplex) crosses indicated hexasomic inheritance. Simplex selections from the Pink Marble progenies were selfed to obtain duplex genotypes with alleles of I on pairing homologues if diploid-like inheritance was occurring. However, subsequent crosses with the nulliplex cv. Canary gave progenies which segregated $4: 1$ (carotenoid $^{-}$:carotenoid $^{+}$, providing strong evidence for a hexasomic mode of inheritance.

\section{INTRODUCTION}

Chromosome numbers in cultivars of the florists' chrysanthemum, Chrysanthemum morifolium Ramat. (Dendranthema morifolium (Ramat.) Tzvelev), have been found to vary between 36 and 75 with a pronounced mode at around 54 (Dowrick, 1953; Endo, 1969a, $b$; Nazeer and Khoshoo, 1983). The basic chromosome number within the genus is nine (Dowrick, 1952; Watanabe, 1977), and C. morifolium has been described as a polyaneuploid complex with the hexaploid form, $2 n=6 x=54$, predominant (Nazeer and Khoshoo, 1983).

Meiotic analysis has shown that bivalents are normally formed (Dowrick, 1953; Nazeer and Khoshoo, 1985). Dowrick (1953) found multivalents in only two cells of the 65 cultivars examined and noted that cultivars with 54 chromosomes invariably formed 27 bivalents; odd-number forms usually had one or more univalents. Nazeer and Khoshoo (1985) found higher frequencies of multivalents but concluded that hexaploids and higher aneuploids showed diploidised meiotic behaviour. Parallel studies with polyploid native Japanese species of Chrysanthemum also showed very high frequencies of bivalent formation (95.599.8 per cent of those possible) which were maintained in tetraploid and hexaploid hybrids but not in triploid, pentaploid or heptaploid hybrids (Watanabe, 1977). It was concluded that meiotic behaviour reflected preferential chromosome pairing between homologues (autosyndesis), with structural differences or genetic control preventing homoeologous pairing, except in the amphihaploid state. Later studies with colchicineinduced polyploids in which bivalent formation was still the norm, led Watanabe (1983) to suggest that multivalent formation is prevented by the restriction of pairing initiation to a single zygomere per chromosome. The consequence of such a mechanism is that all homologous or homoeologous chromosomes within a particular karyotype set may replace each other, leading to non-selective pairing and a multisomic (random chromosome segregation) mode of inheritance. This is in contrast to the diploid-like inheritance which would result if earlier hypotheses of selective pairing are correct. Clarification requires a study of segregation ratios, the subject of this note.

Genetic studies in $C$. morifolium are made difficult by the paucity of simply inherited qualitative characters which have been so far identified, and by the presence of a sporophytic self-incompatibility system (Drewlow et al., 1973). The expression of carotenoid pigmentation in epidermal cells of the corolla is, however, under simple genetic control with the dominant allele I 
(Inhibitor) giving white or pink flowers (depending on whether anthocyanin pigment is absent or present), and with nulliplex forms being yellow or bronze (Langton, 1980; Jordan and ReimannPhilipp, 1983). Segregation ratios for this character in diverse crosses made during the course of routine breeding were analysed to determine the mode of inheritance (Jordan and ReimannPhilipp, 1983), but the results proved equivocal. This reflects the difficulty of distinguishing between the multiplicity of genetic ratios which can be postulated to account for segregation in unstructured crosses, particularly with variation in chromosome number, and the similarities in expectation for diploid-like and multisomic inheritance when $I$ is present in simplex or duplex form (given that dominant alleles can be on nonpairing homoeologues). To circumvent these difficulties of interpretation, a more controlled genetic study is required.

\section{MATERIALS AND METHODS}

\section{Experimental scheme}

Stage 1. Select self-compatible genotypes, nulliplex for the carotenoid inhibitor allele I.

Stage 2. Introduce the dominant allele $I$ in simplex form.

Stage 3. Self-pollinate simplex selections to obtain duplex genotypes with I on pairing homologues if diploid-like inheritance occurs.

Stage 4. Cross the simplex and duplex genotypes obtained at stage 3 with a nulliplex parent and determine subsequent segregation patterns for carotenoid pigmentation. Lack of segregation in the duplex crosses (all carotenoid $^{-}$) would indicate diploidlike inheritance given the selfed origin of the duplex parents. Segregations of $4: 1$ (carotenoid $^{-}:$carotenoid $^{+}$) would suggest random chromosome segregation.

\section{Materials}

Seed progenies of $C$. morifolium segregating for self-compatibility were obtained from Dr W. G. Ronald of the Agriculture Canada Research Station at Morden, Manitoba. Those utilised were 72R-310, 73R-8 and 72R-310-1 ×71-27-25, the parentages of which are given by Ronald and Ascher (1975). Four plants which combined yellow or bronze flower colour (carotenoid ${ }^{+}$) and a prolific self-seeding capacity were selected from these seed progenies for further use. These were C35/3 (ex 72R-310), C36/4 (ex 73R-8) and C37/2 and C.37/3 (ex 72R-310-1×71-27-25). Self-set seed derived from these four selections were flowered in turn; all were carotenoid ${ }^{+}$, confirming the " $\mathrm{C}$ " genotypes as nulliplex for I, (stage 1).

Two commercially grown, carotenoid ${ }^{-}$cultivars, Pink Marble and Pollyanne, were used as female parents in crosses with the self-compatible " $C$ " genotypes, to introduce the dominant allele I. Pink Marble is a "single-flowered" cultivar which fails to liberate its pollen, and Pollyanne is "double-flowered" and generally produces only female ray florets. Neither cultivar had previously given selfed seed. The white-flowered cultivar

Table 1 Carotenoid segregations in progenies derived from cvs. Pink Marble and Pollyanne

\begin{tabular}{|c|c|c|c|c|c|}
\hline \multirow[b]{2}{*}{ Cross } & \multicolumn{2}{|c|}{ Carotenoid } & \multirow{2}{*}{$\begin{array}{l}\text { Test } \\
\text { ratio }\end{array}$} & \multirow[b]{2}{*}{$x^{2}$} & \multirow{2}{*}{$\begin{array}{l}\text { Probability of a larger } \\
\text { value of } \chi^{2} \text { by chance }\end{array}$} \\
\hline & - & + & & & \\
\hline Pink Marble $\times \mathrm{C} 35 / 3$ & 33 & 29 & $1: 1$ & 0.258 & $0 \cdot 61$ \\
\hline Pink Marble $\times$ C $36 / 4$ & 52 & 41 & $1: 1$ & $1 \cdot 304$ & $0 \cdot 25$ \\
\hline Pink Marble $\times \mathrm{C} 37 / 2$ & 39 & 50 & $1: 1$ & $1 \cdot 363$ & $0 \cdot 24$ \\
\hline \multirow[t]{2}{*}{ Pink Marble $\times$ C $37 / 3$} & 14 & 12 & $1: 1$ & $0 \cdot 154$ & $0 \cdot 70$ \\
\hline & 138 & 132 & $1: 1$ & $0 \cdot 133$ & 0.72 \\
\hline Pollyanne $\times \mathrm{C} 35 / 3$ & 147 & 8 & $19: 1$ & 0.008 & 0.93 \\
\hline Pollyanne $\times \mathrm{C} 36 / 4$ & 132 & 5 & $19: 1$ & 0.578 & 0.45 \\
\hline Pollyanne $\times \mathrm{C} 37 / 2$ & 78 & 4 & $19: 1$ & 0.003 & 0.96 \\
\hline \multirow[t]{2}{*}{ Pollyanne $\times \mathrm{C} 37 / 3$} & 97 & 6 & $19: 1$ & $0 \cdot 141$ & 0.71 \\
\hline & 454 & 23 & $19: 1$ & 0.032 & $0 \cdot 86$ \\
\hline Pollyanne $\times$ Bonnie Jean & 448 & 10 & $39: 1$ & 0.189 & 0.66 \\
\hline
\end{tabular}


Bonnie Jean was used in test crosses with Pollyanne. Bonnie Jean has previously been shown to be simplex for I (Langton, 1980).

The nulliplex genotype used as male parent at stage 4 of the experimental scheme was cultivar Canary. Its nulliplex status was inferred following microscopic examination of sections of corolla tissue cut using a freezing microtome. Yellow chromoplasts were clearly visible in the histogenic tissue layer L2, which determines breeding behaviour (Langton, 1980).

\section{Methods}

Crossing techniques broadly followed those outlined by Langton (1976). Paper bags were used to enclose individual blooms to prevent insect-mediated cross-pollination. Possible self-pollination at stage 4 of the experimental scheme was tested by brushing separately bagged blooms of the female parents with a pollen-free brush on each occasion when pollinations with Canary were carried out.

Segregation ratios for carotenoid pigmentation in progenies were assessed by observation of ray floret colour at anthesis. Pink and white blooms were scored as carotenoid ${ }^{-}$whilst bronze and yellow blooms were scored as carotenoid ${ }^{+}$. Hexasomic ratios for random chromatid segregation were not considered since these require the formation of multivalents which are rarely seen.

\section{RESULTS}

\section{Crosses with cultivars Pink Marble and Pollyanne (Stage 2)}

Segregation ratios for the eight progenies are given in table 1. The Pink Marble crosses gave good fits to a $1: 1$ ratio $\left(\right.$ carotenoid $^{-}:$carotenoid $^{+}$) indicating that this cultivar is simplex for I. This interpretation is equally valid whether selective or random chromosome pairing occurs. White and pink plants in these progenies can, in turn, be assumed to be simplex and 56 of these were used at stage 3 .

The Pollyanne crosses gave extremely good fits to a 19:1 ratio which would be expected for triplex $\times$ nulliplex crosses, given random chromosome segregation. Further support for Pollyanne as $\mathrm{I}_{3} \mathrm{i}_{3}$ and random pairing was given in a test cross between Pollyanne and the simplex cultivar Bonnie Jean, where a good fit to the expected 39:1 ratio was obtained (see table 1). Whilst this evidence for hexasomic inheritance is not conclusive, the observed segregation data cannot readily be explained on the basis of selective chromosome pairing (7:1 and 15:1 for triplex $\times$ nulliplex and triplex $\times$ simplex respectively, given dominant alleles on non-pairing homoeologues).

\section{Self-pollinations of simplex selections (Stage 3)}

Fifty-six of the carotenoid plants selected from the Pink Marble crosses and presumed to be simplex were self-pollinated. Thirteen produced fair quantities of seed but, following poor seed germination, only three (B166, B167 and B171) gave appreciable numbers of flowering offspring. Segregation ratios for these are given in table 2 where good fits to a $3: 1$ ratio confirmed that these represented the offspring of simplex selfings. As with the Pink Marble segregation data, this interpretation is equally valid whether selective or random chromosome pairing occurs. One third of the carotenoid $^{-}$offspring can be expected to be duplex for I with dominant alleles on pairing homologues if diploid-like inheritance operates. Two thirds can be expected to be simplex.

Table 2 Carotenoid segregations in progenies derived from self-pollination of presumptive simplex selections

\begin{tabular}{|c|c|c|c|c|c|}
\hline \multirow[b]{2}{*}{ Progeny } & \multicolumn{2}{|c|}{ Carotenoid } & \multirow{2}{*}{$\begin{array}{l}\text { Test } \\
\text { ratio }\end{array}$} & \multirow[b]{2}{*}{$x^{2}$} & \multirow{2}{*}{$\begin{array}{l}\text { Probability of a } \\
\text { larger value of } \\
\chi^{2} \text { by chance }\end{array}$} \\
\hline & - & + & & & \\
\hline B166 & 23 & 9 & $3: 1$ & 0.162 & 0.69 \\
\hline B167 & 23 & 6 & $3: 1$ & 0.300 & 0.58 \\
\hline \multirow[t]{2}{*}{ B171 } & 63 & 17 & $3: 1$ & 0.622 & 0.43 \\
\hline & 109 & 32 & $3: 1$ & 0.408 & 0.52 \\
\hline
\end{tabular}

Crosses of simplex/duplex selections with the nulliplex cultivar, Canary (Stage 4)

A total of 27 carotenoid $^{-}$selections from B166, B167 and B171 were asexually multiplied and then crossed as female parents with Canary. They were used as female parents since most appeared to be functionally sterile, presumably having inherited this characteristic from Pink Marble. Sixteen of the crosses yielded sufficient seed for an analysis of segregation ratios, but three, B200, B213 and B217, demonstrated the capacity for significant self-seed set. Segregation data tested against $1: 1$ and $4: 1$ ratios are given in table 3 .

Eleven of the 16 progenies gave good fits to a $1: 1$ ratio, expected for simplex $\times$ nulliplex crosses. Of the remainder, B202, B203 and B222 gave good fits to the hexasomic $4: 1$ ratio for duplex $\times$ 
Table 3 Carotenoid segregations in progenies derived from crosses between selections simplex or duplex for 1 and the nulliplex $c v$. Canary

\begin{tabular}{|c|c|c|c|c|c|c|}
\hline \multirow[b]{2}{*}{ Progeny } & \multicolumn{2}{|c|}{ Carotenoid } & \multirow{2}{*}{$\begin{array}{l}\chi^{2} \text { for test } \\
\text { ratio of } 1: 1\end{array}$} & \multirow{2}{*}{$\begin{array}{l}\text { Probability of } \\
\text { a larger value } \\
\text { of } x^{2} \text { by chance }\end{array}$} & \multirow{2}{*}{$\begin{array}{l}\chi^{2} \text { for test } \\
\text { ratio of } 4: 1\end{array}$} & \multirow{2}{*}{$\begin{array}{l}\text { Probability of } \\
\text { a larger value } \\
\text { of } \chi^{2} \text { by chance }\end{array}$} \\
\hline & - & + & & & & \\
\hline B198 & 9 & 13 & 0.727 & $0 \cdot 39$ & $21 \cdot 011$ & $<0.01$ \\
\hline B199 & 10 & 19 & $2 \cdot 793$ & $0 \cdot 10$ & $37 \cdot 552$ & $<0.01$ \\
\hline B200* & 16 & 16 & 0.000 & $>0.95$ & $18 \cdot 000$ & $<0.01$ \\
\hline B204 & 13 & 15 & $0 \cdot 143$ & 0.71 & $19 \cdot 723$ & $<0.01$ \\
\hline B207 & 12 & 11 & 0.043 & 0.84 & $11 \cdot 130$ & $<0.01$ \\
\hline B208 & 13 & 14 & 0.037 & $0 \cdot 85$ & $17 \cdot 121$ & $<0.01$ \\
\hline B213* & 9 & 14 & 1.087 & $0 \cdot 30$ & $24 \cdot 011$ & $<0.01$ \\
\hline B214 & 15 & 11 & 0.615 & 0.43 & 8.087 & $<0.01$ \\
\hline B219 & 30 & 32 & 0.065 & $0 \cdot 80$ & $38 \cdot 726$ & $<0.01$ \\
\hline B220 & 20 & 19 & 0.026 & 0.87 & $20 \cdot 103$ & $<0.01$ \\
\hline B221 & 37 & 31 & 0.529 & 0.47 & $27 \cdot 827$ & $<0.01$ \\
\hline B202 & 21 & 6 & $8 \cdot 333$ & $<0.01$ & 0.083 & 0.77 \\
\hline B203 & 43 & 13 & $16 \cdot 071$ & $<0.01$ & 0.362 & 0.55 \\
\hline B21 $7^{*}$ & 76 & 8 & $55 \cdot 048$ & $<0.01$ & $5-762$ & 0.02 \\
\hline B218 & 23 & 11 & $4 \cdot 235$ & $0 \cdot 04$ & $3 \cdot 243$ & 0.07 \\
\hline B222 & 36 & 5 & $23 \cdot 439$ & $<0.01$ & $1 \cdot 561$ & $0 \cdot 21$ \\
\hline
\end{tabular}

* Possibility of some self-seed set

nulliplex. The observed segregation for B218 was intermediate but best fitted a 4:1 ratio. B217 also segregated but there were more carotenoid offspring than expected. It may be significant that this was one of the three progenies where a degree of self-pollination could not be ruled out. Assuming $\mathrm{B} 218$ and $\mathrm{B} 217$ were duplex, the ratio of 11 simplex to 5 duplex fits well the expected $2: 1$ ratio $\left(\chi^{2}=0.031, P=0.86\right)$.

\section{DISCUSSION}

The observed segregations for carotenoid pigmentation in Pollyanne crosses support hexasomic inheritance, but they are not conclusive. Jordan and Reimann-Philipp (1983) investigating segregations involving the dominant allele $\mathrm{A}$ for anthocyanin pigmentation, also found a good fit to a 19:1 ratio in the cross Heyday (anthocyanin ${ }^{-}$) $\times$ T72/E17 (anthocyanin $\left.{ }^{+}\right)\left(\chi^{2}=0.62, \quad P=0.43\right)$. This suggests that T72/E17 was triplex $\left(\mathrm{A}_{3} \mathrm{a}_{3}\right)$ and that random chromosome pairing was operating. However, the cross of T72/E17 with another, presumably nulliplex genotype, T71/181/16 gave an observed segregation of $146: 24$, a highly significant departure from the expected 19:1. Indeed this latter segregation gives an excellent fit to a $7: 1$ ratio for triplex $\times$ nulliplex given diploid-like inheritance and T72/E17 carrying three nonpairing dominant alleles $\left(\mathrm{A}_{1} \mathrm{a}_{1} \mathrm{~A}_{2} \mathrm{a}_{2} \mathrm{~A}_{3} \mathrm{a}_{3}\right)\left(\chi^{2}=\right.$ $0 \cdot 40, P=0.53)$. There is no easy explanation for these conflicting results.
However, the segregations for crosses between selfed carotenoid ${ }^{-}$genotypes and Canary described here do strongly support hexasomic inheritance. Putative duplex types occurred at the expected frequency and these all gave progeny which subsequently segregated for carotenoid pigmentation. Four of the five gave fits to a $4: 1$ ratio at $P>0.05$ and the remaining one at $P>0.01$. No segregation (all carotenoid ${ }^{-}$) would have been expected with diploid-like inheritance; the $3: 1$ ratio for duplex $\times$ nulliplex, with the duplex parent having two non-pairing dominant alleles $\left(\begin{array}{llll}I_{1} i_{1} & I_{2} i_{2} & i_{3} i_{3}\end{array}\right)$, not occurring because of the selfed origin of the duplex parent.

The segregation data for hexasomic inheritance in $C$. morifolium supports the single active zygomere theory of Watanabe (1983) which was suggested on cytological evidence to account for the restriction of chromosome association to bivalent formation. This does not infer that the species, which has a breeding history of 2500 years or more (Dowrick, 1953), is an autopolyploid. Rather, it points to a marked homology which was present or has developed between chromosomes of equivalent karyotype sets of its ancestral species. Circumstantial evidence for such homology is seen in the pentaploid hybrid constructed by Watanabe (1977) between the diploid $C$. boreale and the octoploid, $C$. japonense $v$. octoploid where the extent of bivalent formation could only be explained by homoeologous pairing.

The association of polysomic inheritance and bivalent formation has been demonstrated in 
relatively few species; two examples are the hexaploid Phleum pratense (Nordenskiöld, 1953) and the tetraploid Lotus corniculatus (Dawson, 1941). It is now reasonable to add to these the florists' chrysanthemum, C. morifolium.

Acknowledgements I am indebted to Dr W. G. Ronald of the Agriculture Canada Research Station at Morden, Manitoba for kindly supplying seed progenies of $C$. morifolium segregating for self-compatibility.

\section{REFERENCES}

DAWSON, C. D. R. 1941. Tetrasomic inheritance in Lotus corniculatus L. J. Genet., 42, 49-72.

DOWRICK, G. J. 1952. The chromosomes of Chrysanthemum, I: The species. Heredity, 6, 365-375.

DOWRICK, G. J. 1953. The chromosomes of Chrysanthemum, II: Garden varieties. Heredity, 7, 59-72.

DREWLOW, L. W., ASCHER, P. D. AND WIDMER, R. E. 1973. Genetic studies of self incompatibility in the garden chrysanthemum, Chrysanthemum morifolium Ramat. Theor. Appl. Genet., 43, 1-5.

ENDO, N. 1969a. The chromosome survey on the cultivated chrysanthemums, Chrysanthemum morifolium Ram. I. On the chromosome numbers of cultivated chrysanthemums (Part 1). J. Jpn. Soc. Hortic. Sci, 38, 267-274.

ENDO, N. $1969 b$. The chromosome survey on the cultivated chrysanthemums, Chrysanthemum morifolium Ram. II. On the chromosome numbers of cultivated chrysanthemums (Part 2). J. Jpn. Soc. Hortic. Sci, 38, 343-349.
JORDAN, C. AND REIMANN-PHILIPP, R. 1983. Untersuchungen über Typ und Grad der Polyploidie von Chrysanthemum morifolium Ramat. durch Erbanalysen von zwei Blütenfarbmerkmalen. Z. Pflanzenzuecht., 91, 111-122.

LANGTON, F. A. 1976. Techniques of chrysanthemum breeding. The Chrysanthemum Year Book 1976, Gosling, S. (ed.) National Chrysanthemunı Society, pp. 42-53.

LANGTON, F. A. 1980. Chimerical structure and carotenoid inheritance in Chrysanthemum morifolium (Ramat.). Euphytica, 29, 807-812.

NAZEER, M. A. AND KHOSHOO, T. N. 1983. Variation in the chromosome complement of Chrysanthemum morifolium complex. Nucleus (Calcutta), 26, 22-29.

NAZEER, M. A. AND KHOSHOO, T. N. 1985. Meiotic variations in Chrysanthemum morifolium complex. Nucleus (Calcutta), 28, 35-41.

NORDENSKIÖLD, H. 1953. A genetical study in the mode of segregation in hexaploid Phleum pratense. Hereditas, 39, 469-488.

RONALD, W. G. AND ASCHER, P. D. 1975. Self compatibility in garden Chrysanthemum: Occurrence, inheritance and breeding potential. Theor. Appl. Genet., 46, 45-54.

WATANABE, K. 1977. The control of diploid-like meiosis in polyploid taxa of Chrysanthemum (Compositae). Jpn. J. Genet., 52, 125-131.

WATANABE, K. 1983. Studies on the control of diploid-like meiosis in polyploid taxa of Chrysanthemum. Theor. Appl. Genet., 66, 9-14. 